\title{
On the Common Ground of Thermodynamics and Kinetics: How to Pin Down Overpotential to Reversible Metal Hydride Formation and the Complete Ideal Gas Theory of Reversible Chemical Hydrogen Storage
}

\author{
Roland H. Pawelke
}

\begin{abstract}
Ti-doped $\mathrm{NaAlH}_{4}$ requires at $125^{\circ} \mathrm{C}$ for $\left[\mathrm{AlH}_{4}\right]$ formation more than twice the equilibrium pressure; while it is straightforward to relate this conditional surplus in hydrogenation pressure respective chemical potential to kinetic hindrance, it appears strange that this matter has not been duly theoretically addressed in literature to this day. The interest in identifying such overpotentials is not of purely academic interest but touches a problem of practical significance as the maximum applied (i.e. hydrogenation) pressure is an important threshold to metal hydride tank design. A theorybased tool would be a resource-efficient complement or even alternative to $\mathrm{PCl}$ measurements. This paper tracks the formation overpotential issue down to its root and outlines a simple yet accurate general method based on Arrhenius and van't Hoff data. Rather unexpectedly, the result is also the final missing piece towards a comprehensive understanding of reversible chemical hydrogen storage with regard to attainable hydrogen storage capacity.
\end{abstract}

\section{Introduction}

It is one of the peculiarities of metal hydride chemistry that in the partially reversible Ti-doped $\mathrm{NaAlH}_{4}$ system $\left[\mathrm{AlH}_{4}\right]$ formation requires a hydrogenation pressure substantially above the equilibrium pressure: ${ }^{1-3}$ e.g. about 80 bar at $125^{\circ} \mathrm{C}$ versus an equilibrium pressure of about 29 bar. ${ }^{4}$

This surplus pressure suggests a sizeable kinetic barrier as the equilibrium pressure $p_{\text {eq }}$ would be the marker hydrogenation pressure without kinetic hindrance. Considering the fundamental nature of reversible chemical hydrogen storage - it is essentially classic ideal gas equilibrium thermodynamics - it is a bit puzzling that no general theoretical method for assessing such a chemical overpotential seems to exist in literature. With regard to practical application, the maximum applied hydrogen pressure is the foremost quantity to metal hydride tank design and a simple theory-based tool for identifying overpotential pressure would undoubtedly prove of value to the art.

The problem is that neither the classic kinetic and thermodynamic metal hydride analysis tools - the Arrhenius equation and the van't Hoff equation - point a way how to get a grip on overpotential. Yet they simply must contain this piece of information which actually indicates a blind spot in the hitherto understanding of reversible chemical hydrogen storage in particular and physical chemistry in general. It is of course possible to determine the overpressure experimentally by a pressurecomposition-isotherm $(\mathrm{PCl})$ measurement: apart from that being a time-consuming matter requiring special equipment, this merely displaces the issue to the question which temperature to choose. While $\mathrm{PCl}$ s are a tool of value, they cannot be considered a substitute for a fundamental theoretical answer; hence it is worthwhile and necessary to investigate the nature of chemical overpotential in reversible systems. It is a matter of wider concern as touching the foundations of physical chemistry.

This paper outlines the method for determining the hydrogenation overpotential for any reversible chemical hydrogen sorbent by sole means of thermodynamic and kinetic reaction analysis data. 


\section{Methodical Approach}

A higher conditional pressure to reversibility suggests a chemical overpotential with regard to the equilibrium pressure: for that reason it is sensible to start developing from the van't Hoff equation. For metal hydrides, the van't Hoff equation links the hydrogen equilibrium pressure above the sorbent to the thermodynamic reaction data $\Delta H_{\mathrm{m}}{ }^{\circ}$ and $\Delta S_{\mathrm{m}}{ }^{\circ}$, reflecting reference to the mol hydrogen but using $\Delta H$ and $\Delta S$ without indexes is common in relevant literature. $\Delta H_{\mathrm{m}}{ }^{\circ}$ and $\Delta S_{\mathrm{m}}{ }^{\circ}$ are obtained from an extrapolation of $\ln \left(p_{\text {eq }} / p^{\circ}\right)$ versus $1 / T$ towards standard pressure of $p^{\circ}=1 \mathrm{bar}$, thus the quotient $\Delta H_{\mathrm{m}}{ }^{\circ} / \Delta S_{\mathrm{m}}{ }^{\circ}$ yields the temperature for 1 bar equilibrium pressure above the sorbent, it is a material-specific constant. Equation 1 shows the van't Hoff relation for desorption.

$\ln \left(\frac{p_{\mathrm{eq}}}{\mathrm{p}^{\circ}}\right)=-\frac{\Delta H_{\mathrm{m}}^{\circ}}{\mathrm{R} T}+\frac{\Delta S_{\mathrm{m}}^{\circ}}{\mathrm{R}} \quad$ | for desorption $\Delta H_{\mathrm{m}}{ }^{\circ}$ and $\Delta S_{\mathrm{m}}{ }^{\circ}>0$

Why is equation 1 formulated for desorption if scope rests on the overpotential to metal hydride formation respective the absorption reaction? This may seem counterintuitive but reversibility in the thermodynamic sense is an ideal entity in which two different reaction pathways back and forth do not make sense. That in practice two seemingly different reaction pathways are observed does not unhinge the ideal base conception but is rather owed to the arithmetic sign requirements to $\Delta H_{\mathrm{m}}{ }^{\circ}$ and $\Delta S_{\mathrm{m}}{ }^{\circ}$ with regard to reversibility: the $+p \Delta V$ energy consumed by the volume expansion upon hydrogen absorption $\left(\Delta H_{\mathrm{m}}{ }^{\circ}<0\right)$ suffices for an asymmetry which splits the single reaction pathway into two. Equation 4 schematically illustrates the energy balance of a reversible metal hydride.

$$
\Delta H_{\mathrm{m}, \mathrm{abs}}{ }^{\circ}-\left(E_{\mathrm{a}, \mathrm{abs}}+p \Delta V\right)=-\left(\Delta H_{\mathrm{m}, \mathrm{des}}{ }^{\circ}+E_{\mathrm{a}, \mathrm{des}}\right) \quad \mid \Delta H_{\mathrm{m}, \mathrm{abs}}{ }^{\circ}<0<\left\{\Delta H_{\mathrm{m}, \text { des }}{ }^{\circ} ; E_{\mathrm{a}, \text { des }} ; E_{\mathrm{a}, \text { abs }} ; p \Delta V\right\}
$$

If in equation 4 the reaction enthalpies $\Delta H_{\mathrm{m} \text {, abs }}{ }^{\circ}(-)$ and $\left.\Delta H_{\mathrm{m} \text {, des }}{ }^{\circ}+\right)$ are exchanged by the arithmetic mean in terms of amount $\pm \Delta H_{\mathrm{m}}{ }^{\circ}$, the enthalpies cancel out and leave all quantities not visible to the van't Hoff analysis at parity as by equation 5 , demonstrating the fundamental viability of the line of argument. Equation 5 respective its generalization enables an indirect approach starting from the desorption end of the system for capturing the essence of hydrogenation overpotential at the absorption end. That is because the system is a) reversible and $b$ ) it is only for desorption where the arithmetic sign convention makes for an expedient match: $\Delta H_{\mathrm{m}}{ }^{\circ}, \Delta S_{\mathrm{m}}{ }^{\circ}$ and $E_{\mathrm{a} \text {, des }}$ are all positive.

$$
\begin{aligned}
& -\left(\frac{\Delta H_{\mathrm{m}, \text { abs }}{ }^{\circ}+\Delta H_{\mathrm{m}, \text { des }}{ }^{\circ}}{2}\right)-\left(E_{\mathrm{a}, \text { abs }}+p \Delta V\right)=-\left(\left(\frac{\Delta H_{\mathrm{m}, \text { abs }}{ }^{\circ}+\Delta H_{\mathrm{m}, \mathrm{des}}^{\circ}}{2}\right)+E_{\mathrm{a}, \text { des }}\right) \quad \Rightarrow \\
& -\left(E_{\mathrm{a}, \text { abs }}+p \Delta V\right)=-E_{\mathrm{a}, \text { des }}
\end{aligned}
$$

The following question conveys the essence of the indirect approach: In a reversible metal hydride system, what chemical potential respective pressure is necessary to stop desorption cold at the apex of the activation energy? 
Figure 1 illustrates the hydrogen desorption from a reversible generic metal hydride $\mathrm{MH}_{2}$ in an energy vs. reaction-coordinate scheme, all due quantities have a reference to the mol hydrogen.

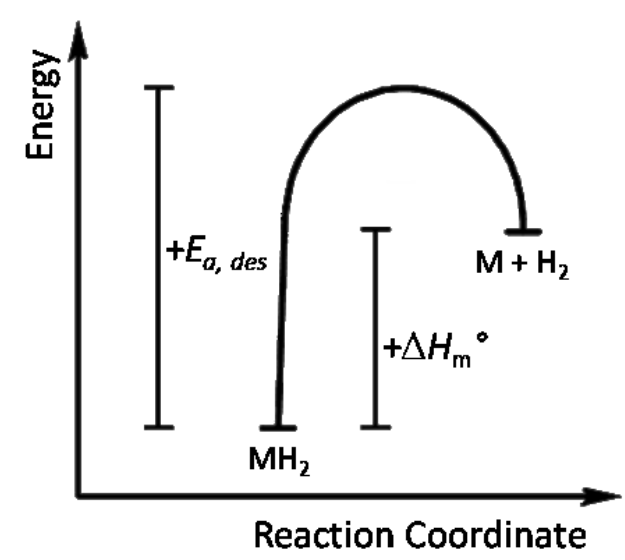

Figure 1: Energy vs. reaction-coordinate scheme for hydrogen desorption from a generic reversible metal hydride $\mathrm{MH}_{2}$.

For a reversible system without activation, changing the equilibrium system from metal hydride into the desorbed state requires the reaction enthalpy $+\Delta H_{m}{ }^{\circ}$ being compensated by the temperatureentropy gain in the gas phase $-T \Delta S_{\mathrm{m}}{ }^{\circ}$; this is possible up to the equilibrium pressure $p_{\text {eq. }}$. Figure 1 shows that the material proportion of the system moves energetically uphill in the desorption process which requires overcoming the activation energy barrier $E_{\mathrm{a} \text {, des. }}$. However, as desorption activation energy $E_{\mathrm{a} \text {, des }}$ encompasses the reaction enthalpy $+\Delta H_{\mathrm{m}}{ }^{\circ}$, the overpotential $E^{*}$ that must be additionally compensated by the temperature-entropy gain $-T \Delta S_{\mathrm{m}}{ }^{\circ}$ is given by $E^{*}=E_{\mathrm{a} \text {, des }}-\Delta H_{\mathrm{m}}{ }^{\circ}$ which is shown in equation 6 .

$E_{\mathrm{a}, \text { des }}-\Delta H_{\mathrm{m}}{ }^{\circ}=E^{*} \Rightarrow E^{*}-T \Delta S_{\mathrm{m}}{ }^{\circ}=0 \quad \mid\left\{E_{\mathrm{a}, \text { des }} ; \Delta H_{\mathrm{m}}{ }^{\circ} ; \Delta S_{\mathrm{m}}{ }^{\circ}>0\right\}$

The overpotential $E^{*}$ in equation 6 stands in two relations to the van't Hoff parameters: first, division by $\Delta S_{\mathrm{m}}{ }^{\circ}$ yields $T^{*}$ which is the temperature rendering desorption versus 1 bar pressure viable.

Second, division of $E^{*}$ by the material constant $\Delta H_{\mathrm{m}}{ }^{\circ} \Delta S_{\mathrm{m}}{ }^{\circ}=T_{1 \mathrm{bar}}$ yields the hypothetical entropy gain $\Delta S_{\mathrm{m}}{ }^{*}$ which would be required for the activated system adopting an equilibrium pressure of $1 \mathrm{bar}$ at the metal hydride specific temperature $T_{1 \mathrm{bar}}$. This is shown in equations $7 \mathrm{a}$ and $7 \mathrm{~b}$, respectively.

$$
\begin{aligned}
& \frac{E^{*}}{\Delta S_{\mathrm{m}}{ }^{\circ}}=T^{*} \\
& \frac{E^{*}}{T_{1 \mathrm{bar}}}=\Delta S_{\mathrm{m}}{ }^{*} \text { 。 }
\end{aligned}
$$

Setting the van't Hoff equation up for $T=T^{*}$ with $\Delta S_{\mathrm{m}}{ }^{*}$ in lieu of $\Delta S_{\mathrm{m}}{ }^{\circ}$ yields the sought expression for the marker equilibrium hydrogen pressure $p^{*}$ caused by overpotential, as shown in equation 8 . 
$\ln \left(\frac{p^{*}}{p^{\circ}}\right)=-\frac{\Delta H_{m}^{\circ}}{R T^{*}}+\frac{\Delta S_{m}^{0^{*}}}{R} \quad \mid\left\{\Delta H_{m}{ }^{\circ} ; \Delta S_{m}^{0^{*}}>0\right\}$

This can be made more apparent if equation 8 is transformed into the form which equals the chemical potential of the gas phase with the $2^{\text {nd }}$ law of thermodynamics, shown in equation 9 .

$\mathrm{R} T^{*} \ln \left(\frac{p^{*}}{p^{\circ}}\right)=-\Delta H_{\mathrm{m}}{ }^{\circ}+T^{*} \Delta S_{\mathrm{m}}{ }^{{ }_{0}} \quad \mid\left\{\Delta H_{\mathrm{m}}{ }^{\circ} ; \Delta S_{\mathrm{m}}^{0^{*}}>0\right\}$

Division of equation 9 by $\Delta H_{\mathrm{m}}{ }^{\circ}$ turns the $\Delta S_{\mathrm{m}}{ }^{{ }^{*}}$ entropy term into a temperature proportionality term (equal by the ideal gas law to a quotient of $p V_{\mathrm{m}}$-energies). This is shown in equations $10 \mathrm{a}$ and $10 \mathrm{~b}$.

$\frac{\mathrm{R} T^{*}}{\Delta H_{\mathrm{m}}{ }^{\circ}} \ln \left(\frac{p^{*}}{\mathrm{p}^{\circ}}\right)=-1+\frac{T^{*} \Delta S_{\mathrm{m}}{ }^{*}}{\Delta H_{\mathrm{m}}{ }^{\circ}}=-1+\frac{T^{*}}{T_{1 \mathrm{bar}}}\left(\frac{E_{\mathrm{a}, \text { des }}}{\Delta H_{\mathrm{m}}{ }^{\circ}}-1\right)$

$\frac{\Delta S_{\mathrm{m}}{ }^{*} \mathrm{o}}{\Delta H_{\mathrm{m}}{ }^{\circ}}=\frac{E^{*}}{T_{1 \mathrm{bar}} \Delta H_{\mathrm{m}}{ }^{\circ}}=\frac{1}{T_{1 \mathrm{bar}}}\left(\frac{E_{\mathrm{a}, \text { des }}-\Delta H_{\mathrm{m}}{ }^{\circ}}{\Delta H_{\mathrm{m}}{ }^{\circ}}\right)=\frac{1}{T_{1 \mathrm{bar}}}\left(\frac{E_{\mathrm{a}, \text { des }}}{\Delta H_{\mathrm{m}}{ }^{\circ}}-1\right)$

$\mathrm{R} T^{*} \ln \left(\frac{p^{*}}{\mathrm{p}^{\circ}}\right)=\left(\frac{T^{*}}{T_{1 \mathrm{bar}}}\left(\frac{E_{\mathrm{a}, \text { des }}}{\Delta H_{\mathrm{m}}{ }^{\circ}}-1\right)-1\right) \Delta H_{\mathrm{m}}{ }^{\circ}=\left(\frac{T^{*}}{T_{1 \mathrm{bar}}}\left(\frac{E_{\mathrm{a}, \text { des }}}{\Delta H_{\mathrm{m}}{ }^{\circ}}-1\right)\right) \Delta H_{\mathrm{m}}{ }^{\circ}-\Delta H_{\mathrm{m}}{ }^{\circ}$

The left side of equation $10 \mathrm{~b}$ is the chemical potential of the gas phase at temperature $T^{*}$ at which the temperature-entropy gain in the system $-T^{*} \Delta S_{m}{ }^{\circ}$ caused by hydrogen desorption suffices for compensating the kinetic barrier to the equilibrium system. The right side is an expression of energy differences illustrated in figure 1 but expressed in terms of $\Delta H_{m}{ }^{\circ}$. The term $\left(E_{a, \text { des }} / \Delta H_{m}{ }^{\circ}-1\right)$ expresses the activation energy $E_{\mathrm{a} \text {, des }}$ in multiples of $\Delta H_{\mathrm{m}}{ }^{\circ}$ and subtracts the one $\Delta H_{\mathrm{m}}{ }^{\circ}$ which is accounted for by the equilibrium system. That factor is multiplied with a quotient of the fix temperatures $T^{*} / T_{1 \mathrm{bar}}$ for reflecting the ratio of $E^{*} / \Delta H_{\mathrm{m}}{ }^{\circ}$. From equation $10 \mathrm{~b}$, the argumentative tacking from desorption towards absorption requires the realization that the summand $-\Delta H_{\mathrm{m}}{ }^{\circ}$ on the right side if $\Delta H_{\mathrm{m}}{ }^{\circ}>0$ is equivalent to the addition of the negative absorption reaction enthalpy. For this reason, equation 11 shows the definite ideal gas expression for the marker equilibrium pressure $p^{*}$ caused by chemical overpotential on basis of Arrhenius and van't Hoff analysis data.

$$
\begin{aligned}
& \ln \left(\frac{p^{*}}{p^{\circ}}\right)=\left(\frac{T^{*}}{T_{1 \mathrm{bar}}}\left(\frac{E_{\mathrm{a}, \text { des }}}{\Delta H_{\mathrm{m}}{ }^{\circ}}-1\right)-1\right) \frac{\Delta H_{\mathrm{m}}{ }^{\circ}}{\mathrm{R} T^{*}} \\
& T^{*}=\frac{E_{\mathrm{a}, \text { des }}-\Delta H_{\mathrm{m}}{ }^{\circ}}{\Delta S_{\mathrm{m}}{ }^{\circ}} \quad T_{1 \mathrm{bar}}=\frac{\Delta H_{\mathrm{m}}{ }^{\circ}}{\Delta S_{\mathrm{m}}{ }^{\circ}}
\end{aligned}
$$




\section{Results}

It is consequential to apply equation 11 to the overpotential issue encountered in the $\mathrm{Ti}^{-\mathrm{NaAlH}_{4}}$ system. The Arrhenius activation energy values for $\left[\mathrm{AlH}_{4}\right]$ formation depend on Ti-concentration and range from $72.8 \mathrm{~kJ}\left(\mathrm{~mol} \mathrm{H}_{2}\right)^{-1}$ for $0.9 \mathrm{~mol} \%$ Ti-doped $\mathrm{NaAlH}_{4}$ to $80 \mathrm{~kJ}\left(\mathrm{~mol} \mathrm{H}_{2}\right)^{-1}$ for $4 \mathrm{~mol} \%$ Ti-doped $\mathrm{NaAlH}_{4}$ as by SANDROCK et $a l^{4}{ }^{4}$ The van't Hoff reaction parameters base on the data of BOGDANOVIĆ et al for $1.3 \mathrm{~mol} \%$ Ti-doped $\mathrm{NaAlH}_{4}{ }^{1}{ }^{1}$ The $4 \mathrm{~mol} \%$ Ti-case will be considered for an example:

$\ln \left(\frac{p^{*}}{p^{\circ}}\right)=\left(\frac{T^{*}}{T_{1 \mathrm{bar}}}\left(\frac{E_{\mathrm{a}, \text { des }}}{\Delta H_{\mathrm{m}}{ }^{\circ}}-1\right)-1\right) \frac{\Delta H_{\mathrm{m}}{ }^{\circ}}{\mathrm{R} T^{*}} \quad \mid T^{*}=\frac{E_{\mathrm{a}, \text { des }}-\Delta H_{\mathrm{m}}{ }^{\circ}}{\Delta S_{\mathrm{m}}{ }^{\circ}} \quad T_{1 \mathrm{bar}}=\frac{\Delta H_{\mathrm{m}}{ }^{\circ}}{\Delta S_{\mathrm{m}}{ }^{\circ}}$

$$
\begin{array}{lll}
\Delta H_{\mathrm{m}}{ }^{\circ}=+37 \mathrm{~kJ}\left(\mathrm{~mol} \mathrm{H}_{2}\right)^{-1} \quad \Delta S_{\mathrm{m}}{ }^{\circ}=+121 \mathrm{~J}\left(\mathrm{~mol} \mathrm{H}_{2}\right)^{-1} \mathrm{~K}^{-1} & E_{\mathrm{a}, \text { des }}=80 \mathrm{~kJ}\left(\mathrm{~mol} \mathrm{H}_{2}\right)^{-1} \\
T_{1 \mathrm{bar}}=306 \mathrm{~K} & T^{*}=355 \mathrm{~K} \quad \Rightarrow \quad \ln \left(p^{*} / \mathbf{p}^{\circ}\right)=4.365(6) \Rightarrow \boldsymbol{p}^{*}=78.7 \mathrm{bar} \approx 79 \mathrm{bar}
\end{array}
$$

\section{Discussion}

This result for a marker pressure of $p^{*}=79$ bar for $\left[\mathrm{AlH}_{4}\right]$ formation complies perfectly with the reported minimum hydrogenation pressure of 79.5 bar by SANDROCK et al whose activation energy value is used, ${ }^{4}$ although SANDROCK et al do not mention this as result of an optimization effort. Yet it is unlikely that such an important experimental quantity would be left to chance at Sandia National Laboratory. The value of $T^{*}=355 \mathrm{~K}$ or $82^{\circ} \mathrm{C}$ is also in fine agreement with the empiric yet somewhat unspecific observation that desorption from $\mathrm{Ti}^{-N_{a A l H}}$ materials becomes noticeable above ca. 80 ${ }^{\circ} \mathrm{C}$. The reason for that and how that temperature can be generally calculated from the kinetic and thermodynamic analysis data is now clear. Ti-concentrations below $1 \mathrm{~mol} \%$ show considerably lower activation energies but the benefit is offset by the lower catalyst concentration; hence the potentially relevant Ti-concentrations are likely between $2-4 \mathrm{~mol} \%$ for which near-identical activation energies are reported: $79.5 \mathrm{~kJ}\left(\mathrm{~mol} \mathrm{H}_{2}\right)^{-1}$ and $80 \mathrm{~kJ}\left(\mathrm{~mol} \mathrm{H}_{2}\right)^{-1}$, respectively. Equation 11 works of course only as well as the kinetic and thermodynamic data allow and already a deviation of a few $\mathrm{kJ}\left(\mathrm{mol} \mathrm{H}_{2}\right)^{-1}$ in activation energy $E_{\mathrm{a} \text {, des }}$ will result in an exponential error to the overpotential pressure $p^{*}$. However, the approach allows retro-checking for consistency, also with regard to experiment. In the present case the kinetic and thermodynamic data by Sandia National Laboratory and MPI für Kohlenforschung match as indicated by the common $T_{1 \text { bar }}$ temperature of $306 \mathrm{~K}^{5}$

In relation to the wider contexts of metal hydride chemistry and natural science, it is surprising to say the least that something as fundamental as equation 11 can convey new insight by the early $21^{\text {st }}$ century; nothing could be found in all of literature suggesting the contrary. The relevant works of Arrhenius and van't Hoff appeared towards the end of the $19^{\text {th }}$ century and even the Ti-NaAlH papers referenced to date back to the turn of the millennium, with the entire $20^{\text {th }}$ century in between. Evidently, a better late than never applies, yet what might be the reason(s) for that?

Thermodynamics and kinetics are commonly taught as separate entities: thermodynamics tell whether a reaction is possible, kinetics tell about the speed of possible reactions. That educational separation favours the instalment of a rift on the mind and overpotential is usually understood as a kinetic problem for the activation energy is determined from kinetic analysis. However, it shows for the reversible case that the matter is ultimately of thermodynamic nature as no time-based quantity 
appears throughout the entire line of argument. The overpotential $E^{*}$ actually represents the kinetic hydrogen retention potential of a metal hydride, a silent reserve to the $\Delta H_{m}{ }^{\circ}$ equilibrium capacity!

This important realization sorts out every hitherto unclear principal aspect of reversible chemical hydrogen storage: first, it clarifies the nature of high activation, high hydrogen content but comparatively low reaction enthalpy hydrides, e.g. borohydrides. ${ }^{6}$ From the common fragmented understanding of thermodynamics and kinetics, these systems must appear by principle fully reversible with an appealingly low $T_{1 \mathrm{bar}}$ temperature, so virtually all that would be needed for a marvellous energy storage density is getting rid of the activation barrier. However, in light of the present work rather the opposite appears to be true, these low $\Delta H_{\mathrm{m}}{ }^{\circ}$ materials are of high hydrogen content exactly because of their high activation energy and removal of that barrier may render the system reversible but within the modest thermodynamic limits to reversible mass transfer previously outlined. ${ }^{7}$ However, it also shows now that an all-equilibrium perspective does not capture the full picture either.

Towards that end a revision of thermodynamic tailoring is due, ${ }^{8-10}$ one of the classic prime R\&D approaches in metal hydride chemistry though a bit beyond its heyday. The concept has a fairly strong record with interstitial hydrides, ${ }^{11-14}$ but the notion cannot be helped that it did never really evolve beyond a methodical, rather material-specific level. Employing the concept in wider context e.g. for predicting new complex hydrides did not go well, ${ }^{15}$ and at large it failed to provide conclusive insight about the nature of doping effects in complex hydrides. Historically that may have helped to promote a fractured, functional understanding with regard to metal hydride classes or even individual systems thereof: that metal hydride R\&D must be all about material properties, methods and measuring at no higher connecting principle. It is not clear how the vital equilibrium relation to the gas phase could ever be considered a secondary quantity in relation to the sorbent phase - it is simply folly - and it is even less comprehensible how that folly eventually made scientific consensus.

Declaring the essential non-essential frees, of course, from the dreadful shackles of causality which is good for promises but bad for result convergence. In sum, the best which can ensue from that is inconclusiveness, at large a proper stocktaking of metal hydride hydrogen storage R\&D as a whole: a few exceptional papers do not belie that fact as it shows that even these rather accidentally hit the thermodynamic boundaries to reversible mass transfer as result of educated guess, trial and error. While it is hard to think of a stronger case for why a positivist materialistic utilitarian bias should not make for the final philosophy of science, it is ultimately secondary whether said bias is ardently defended as an article of faith or has been silently abandoned due to persistent failure. It did not work out in convergent manner for decades and good scientific R\&D questions yield convergent insight by definition. Discussing some sort of scientific-method-assisted-policy-making in terms of science is fruitless; they simply do not compare. Even if all possible permutations by the periodic table were studied in material-bias sense (which kind of happened), convergence in insight would remain elusive for the initial first sin of declaring the essential non-essential. To this day, there is no understanding of what reversible chemical hydrogen storage is about or can be all about.

A convergent comprehensive view on reversible chemical hydrogen storage requires essentially the ideal gas law, the $2^{\text {nd }}$ law of thermodynamics, van't Hoff and Arrhenius analysis: it is $19^{\text {th }}$ century material plus some wits. The various reversible metal hydride material classes such as interstitial, complex or salt-like have undoubtedly their chemical peculiarities but at large each of them corresponds to a chemical potential domain of gaseous hydrogen, ${ }^{16}$ according to the nature of the hydrogen-metal bond respective its strength. That follows compellingly from the equilibrium 
character of the reversible process: there is by principle a $\Delta H_{\mathrm{m}}{ }^{\circ}$ reaction enthalpy continuum of hydrogen storage materials from cryo-physisorption materials to high-temperature metal hydrides.

With all vital findings pre-dating 1900 , the sentence passes firmly that reversible chemical hydrogen storage, as a reflection of reversible chemical mass transfer, has not been really understood by anybody to this day; documented hint in literature suggesting the faintest of the contrary will be appreciated, the author could not find any by best of effort. That the answer to it all has been totally overseen for over a century might be simply for the reason that it hid in fairly open sight.

This leads back to the statement that the hitherto understanding of thermodynamic tailoring must be considered incomplete either, proving which is simple enough: if thermodynamic tailoring were a principle well understood, there should have been a long time ago a sound explanation for the two cases where it actually made a handsome difference. These are the $\mathrm{K} / \mathrm{Ti}$-co-doped- $\mathrm{NaAlH}_{4}$ system and the $\mathrm{Rb} / \mathrm{K}$-co-doped $2 \mathrm{LiH} / \mathrm{Mg}\left(\mathrm{NH}_{2}\right)_{2}$ system, the respective publications dating back to 2005 and $2014 .{ }^{17,18}$ With the exception of a couple of working papers by the author touching the matter, ${ }^{7,19}$ the number of comprehensive explanations or even attempts thereof in literature figures to nil.

The final argument towards the complete ideal gas theory of reversible chemical hydrogen storage will be made by means of the older $\mathrm{K} / \mathrm{Ti}$-co-doped-NaAlH ${ }_{4}$ case: ${ }^{17}$ The substitution of just $4 \mathrm{~mol} \% \mathrm{Na}$ by $\mathrm{K}$ in a $4 \mathrm{~mol} \%$ Ti-doped $\mathrm{NaAlH}_{4}$ raises the reversible hydrogen storage capacity from $3.3 \% \mathrm{w} / \mathrm{w} \mathrm{H}$ to $4.7 \% \mathrm{w} / \mathrm{w} \mathrm{H}$, a massive increase by $42 \%$ but leaving the van't Hoff reaction parameters virtually unscathed. The author previously made a point about the thermodynamic limitation to ideal reversible mass transfer, amounting to $12 \mathrm{~kJ}\left(\mathrm{~mol} \mathrm{H}_{2}\right)^{-1}$ per mass percent hydrogen storage capacity by sum formula, which relates to the desorption enthalpy $\Delta H_{\mathrm{m}}{ }^{\circ}{ }^{7}$

That theorem applies well to the standard equilibrium $\Delta H_{\mathrm{m}}{ }^{\circ}$ enthalpy case of metal hydrides (Ti$\mathrm{NaAlH}_{4}$ shows a $\Delta H_{\mathrm{m}}{ }^{\circ}$ of ca. $40 \mathrm{~kJ}\left(\mathrm{~mol} \mathrm{H}_{2}\right)^{-1}$ over both desorption stages) ${ }^{1,17}$ However, the disruptive raise seen with the $\mathrm{K} / \mathrm{Ti}$-co-doped material cannot be explained by it alone as the van't Hoff data virtually remain unaffected by the modification and for a new equilibrium there should have been an according enthalpy change to $\Delta H_{\mathrm{m}}{ }^{\circ}$. Yet the equilibrium approach still proves of value: on one hand, it provides the new reaction pathway, associated with the formation of $\mathrm{K}_{2} \mathrm{NaAlH}_{6}$ (it works even better for the $\mathrm{Rb} / \mathrm{K}$-co-doped $2 \mathrm{LiH} / \mathrm{Mg}\left(\mathrm{NH}_{2}\right)_{2}$ system $)^{7}$ and on the other, the increase to equilibrium hydrogen storage capacity also shows in the averaged metal hydride phase molar volumes. ${ }^{19}$ The latter finding was not within first intention of said work but rather accidental; yet it represents a first approach on the overpotential issue from a sorbent material bias. Although fairly successful in its own right, it suffers from the complex, specific nature of the sorbent-bias either. Molar volume is neither a handy nor general quantity but with a sorbent-bias it is the best choice. Due to equilibrium, a gas-phase centred way of expressing the same by means of pressure and temperature must exist.

Evidently, the equilibrium approach unveils much but not the complete picture: ${ }^{7,19}$ it works fine for the equilibrium case and provides a principal idea how thermodynamic tailoring gets a surplus to the equilibrium hydrogen amount into the sorbent phase. Yet the one final principal question of how that surplus hydrogen gets permanently fixated in the sorbent phase, it cannot answer.

This work unveiled a straightforward answer to that open question: the surplus is kinetically retained by means of the activation energy of the base equilibrium system! That this was not realized earlier may underscore how the educationally instilled rift between thermodynamics and kinetics preshapes thought and how obstructive to seeing clearly that may be. A revision of how this is taught in curriculums may be due: showing the convergence of thermodynamics and kinetics in reversible systems is at least equally important to teaching the functional separation for irreversible ones. 
The true significance of this work does not rest with hydrogen storage and as such it does not matter whether it is considered a "hot" topic or not because proper fundamental ideas never get outdated.

\section{Conclusion}

This paper closes the circle to the beginning of this line of work dedicated to the fundamental nature of reversible chemical hydrogen storage with regard to attainable hydrogen storage capacity. The preceding working results need some re-phrasing and re-arrangement for a complete principal ideal gas theory of reversible chemical hydrogen storage in five articles (hydrogen may be approximated as ideal for typical reversible metal hydride reaction conditions):

\$1 Although derived from an equilibrium approach, ${ }^{7}$ the finding that $12 \mathrm{~kJ}\left(\mathrm{~mol} \mathrm{H}_{2}\right)^{-1}$ are needed for the reversible mass transfer of one percent hydrogen by sum formula is ultimately not limited to the equilibrium case. In the end, it is not relevant whether the retention belongs to a reversible process or not: it is that retaining 1 mass percent hydrogen by sum formula in a sorbent requires 12 $\mathrm{kJ}\left(\mathrm{mol} \mathrm{H}_{2}\right)^{-1}: 12 \mathrm{~kJ}\left(\mathrm{~mol} \mathrm{H}_{2}\right)^{-1}[1 \% \mathrm{w} / \mathrm{w} \mathrm{H}]^{-1}$ is the unit of mass-transfer in reversible metal hydrides.

\$2 The reaction enthalpy $\Delta H_{\mathrm{m} \text {, eq }}{ }^{\circ}$ of a metal hydride is a measure for the equilibrium hydrogen storage capacity in relation to $\$ 1$. There is an effect of average metal hydride particle size on the value of $\Delta H_{\mathrm{m} \text {, eq }}$, too. $^{7}$ Yet a new reaction pathway may be introduced into the system by doping for a metal hydride of much higher formation enthalpy $\Delta H_{\mathrm{m} \text {, dopant }}{ }^{\circ}{ }^{19}$ As an empiric rule, the doping may have up to about $4 \mathrm{~mol} \%$ a favourable impact on the equilibrium system before adverse effects start to show. Furthermore, the viability of this concept seems to be bound to a chemical compliance with the equilibrium system in terms of mass transfer, as observed for $\mathrm{K}_{2} \mathrm{NaAlH}_{6}$ with $\mathrm{Ti}^{-} \mathrm{NaAlH}_{4}{ }^{19}$

\$3 There can be a thermodynamic and a kinetic proportion to the perceived reversible hydrogen storage capacity (applying also by principle to metastable hydrides). An enhancement of reversible hydrogen storage capacity by doping in the sense of $\S 2$ may be envisioned in two steps: first, the surplus-to-equilibrium hydrogen amount is pumped into the sorbent phase in equilibrium manner where second, it is retained by means of the kinetic hindrance to the equilibrium system. By principle, this resolves the mystery how it can be possible to substantially increase the reversible hydrogen amount by doping while the thermodynamic reaction data of the base equilibrium system remain virtually unchanged. The roles of doping agent and activation energy are dialectically intertwined. The margin for kinetic retention is thus the overpotential $E^{*}=E_{\mathrm{a}}$, des $-\Delta H_{\mathrm{m} \text {, eq }}$. Therefore, a sufficiently large activation energy becomes instrumental for a high hydrogen amount by sum formula if $\Delta H_{\mathrm{m} \text {, eq }}{ }^{\circ}$ is far from abiding by the $12 \mathrm{~kJ}\left(\mathrm{~mol} \mathrm{H}_{2}\right)^{-1}[1 \% \mathrm{w} / \mathrm{w} \mathrm{H}]^{-1}$ criterion.

\$4 If there were a way of doping without mass abatements and always a suitable metal hydride of appropriate reaction enthalpy available, by principle any partially reversible metal hydride could be made fully reversible with regard to the sum formula of the base system. As a matter of course, mass abatements and metal hydride availability constraints apply in practice.

\$5 a. The below relation shows the theoretical expendable surplus in activation energy $\Delta E_{\mathrm{a} \text {, exp }}$ in $\mathrm{kJ}(\mathrm{mol} \mathrm{H})^{-1}$ of a doped equilibrium system in the sense of $\S 2$, with $E^{*}=E_{\mathrm{a} \text {, des }}-\Delta H_{\mathrm{m} \text {, eq }}$.

$E^{*}-\left([\Delta \% \mathrm{w} / \mathrm{w} \mathrm{H}]_{\mathrm{rev}}-\frac{\Delta H_{\mathrm{m}, \mathrm{eq}}{ }^{\circ}[1 \% \mathrm{w} / \mathrm{w} \mathrm{H}]}{12 \mathrm{~kJ}\left(\mathrm{~mol} \mathrm{H}_{2}\right)^{-1}}\right) \cdot 12 \mathrm{~kJ}\left(\mathrm{~mol} \mathrm{H}_{2}\right)^{-1}[1 \% \mathrm{w} / \mathrm{w} \mathrm{H}]^{-1}=\Delta E_{\mathrm{a}, \exp }$

$[\Delta \% \mathrm{w} / \mathrm{w} \mathrm{H}]_{\mathrm{rev}}$ represents either the apparent experimental reversible hydrogen amount or in relation to the definition of $R \& D$ targets, the target reversible specific hydrogen amount. With regard to the latter, a metal hydride at the end of its kinetic retention potential may be rendered 
capable of fixating more hydrogen by a combination of kinetic stabilization and appropriate doping; that is at least in theory and such an increase must come at the expense of attainable reaction rate.

b. Complementary to $\S 5$ a, the maximum hydrogen surplus to the equilibrium amount resulting from a doping process is given by the $\Delta H_{\mathrm{m} \text {, dopant }}{ }^{\circ}$ reaction enthalpy times molar concentration $c_{\text {mol\%, dopant }}$ divided by $12 \mathrm{~kJ}\left(\mathrm{~mol} \mathrm{H}_{2}\right)^{-1}[1 \% \mathrm{w} / \mathrm{w} \mathrm{H}]^{-1}$.

c. Therefore, the theoretical maximum total reversible hydrogen amount $[\Delta \% \mathrm{w} / \mathrm{w} \mathrm{H}]_{\mathrm{rev}, \max }$ of a doped equilibrium metal hydride system is given by the following relation:

$[\Delta \% \mathrm{w} / \mathrm{w} \mathrm{H}]_{\mathrm{rev}, \max }=\frac{\Delta H_{\mathrm{m}, \text { eq }}{ }^{\circ}+\Delta H_{\mathrm{m}, \text { dopant }}{ }^{\circ} \cdot c_{\mathrm{mol} \% \text {, dopant }}}{12 \mathrm{~kJ}\left(\mathrm{~mol} \mathrm{H}_{2}\right)^{-1}}[1 \% \mathrm{w} / \mathrm{w} \mathrm{H}]$

Which is on the conditions that $\left(\Delta H_{\mathrm{m} \text {, dopant }}{ }^{\circ} \cdot c_{\text {mol\%, dopant }}\right) \leq E^{*}=E_{\mathrm{a} \text {, des }}-\Delta H_{\mathrm{m} \text {, eq }}{ }^{\circ}$ and that the doping agent concentration $c_{\text {mol\%, dopant }}$ do not adversely affect the equilibrium system.

These five articles suffice for a principal, convergent and consistent image of the entirety of metal hydride chemistry while being firmly rooted in the $19^{\text {th }}$ century fundamentals of physical chemistry: all falls into place, the hard experimental facts, the half-truths and even the nonsense. Furthermore, it marks out the immovable margin for results that more sophisticated methods may exploit.

While developed for reversible chemical hydrogen storage, these relations must be of significance to other reversible chemical systems in adjusted form, e.g. those of electrochemistry: for if reversible hydrogen transfer across phase boundaries is limited by thermodynamics, by principle any must be.

\section{Acknowledgements}

This paper spun-off from the author's primary line of work done at FOTEC Forschungs- und Technologietransfer GmbH under European Space Agency grant 4000105330/12/NL/CLP and European Defence Agency contract A-1341-RT-GP which is gratefully acknowledged.

\section{Conflicts of Interest}

There are no conflicts of interest to declare.

\section{References}

1 B. Bogdanović, R. A. Brand, A. Marjanović, M. Schwickardi and J. Tölle, J. Alloys Compd., 2000, 302, 36-58.

2 G. Streukens, B. Bogdanović, M. Felderhoff and F. Schüth, Phys Chem Chem Phys, 2006, 8, 2889-2892.

3 B. Bogdanović, U. Eberle, M. Felderhoff and F. Schüth, Scr. Mater., 2007, 56, 813-816.

4 G. Sandrock, K. Gross and G. Thomas, J. Alloys Compd., 2002, 339, 299-308.

5 K. J. Gross, G. J. Thomas and C. M. Jensen, J. Alloys Compd., 2002, 330-332, 683-690.

6 H.-W. Li, Y. Yan, S. Orimo, A. Züttel and C. M. Jensen, Energies, 2011, 4, 185-214.

7 R. H. Pawelke, The Master Key to the Problem of Reversible Chemical Hydrogen Storage is $12 \mathrm{~kJ}\left(\mathrm{~mol} \mathrm{H}_{2}\right)^{-1}, 2019$.

8 M. Dornheim, Thermodynamics of Metal Hydrides: Tailoring Reaction Enthalpies of Hydrogen Storage Materials, INTECH Open Access Publisher, 2011.

9 Y. Liu, Y. Yang, M. Gao and H. Pan, Chem. Rec., 2016, 16, 189-204.

10 D. Stolten and T. Grube, Eds., 18th World Hydrogen Energy Conference 2010 - WHEC 2010: proceedings. 4: Parallel sessions book: storage systems, policy perspectives, initiatives and cooperations, Forschungszentrum, IEF-3, Jülich, 2010.

11 K. H. J. Buschow, P. C. P. Bouten and A. R. Miedema, Rep. Prog. Phys., 1982, 45, 937-1039.

12 J. F. Herbst, J. Alloys Compd., 2002, 337, 99-107.

13 Z. Liu, F. Ruan, Y. Li, T. Zhai, M. Zhao and J. Zhang, Intermetallics, 2019, 105, 79-91.

14 P. Ngene, A. Longo, L. Mooij, W. Bras and B. Dam, Nat. Commun., 2017, 8, 1846.

15 H. A. Aebischer and L. Schlapbach, Z. Für Phys. Chem., 1993, 179, 21-25.

16 H. Hemmes, A. Driessen and R. Driessen, J Phys C, 1986, 3571-3585.

17 P. Wang, X.-D. Kang and H.-M. Cheng, J. Appl. Phys., 2005, 98, 074905.

18 C. Li, Y. Liu, R. Ma, X. Zhang, Y. Li, M. Gao and H. Pan, ACS Appl. Mater. Interfaces, 2014, 6, 17024-17033.

19 R. H. Pawelke, How to Assess the Relative Volume Change of Reversible Metal Hydrides Easily, Speedily and Concisely (Enough) with a Surprising Relevance for Clarifying Thermodynamic Tailoring Effects, 2019. 